\title{
Verification of the ROSFOND/ABBN nuclear data based on the OECD/NEA benchmark on criticality safety of mox-fueled systems ${ }^{*}$
}

\author{
Olga N. Andrianova ${ }^{1}$, Yury Ye. Golovko ${ }^{1}$, Gennady N. Manturov ${ }^{1}$ \\ 1 JSC “SSC RF-IPPE n.a. A.I. Leypunsky”, 1 Bondarenko sq., Obninsk, Kaluga reg., 249033 Russian Federation \\ Corresponding author: Olga N.Andrianova (oandrianova@ippe.ru)
}

Academic editor: Georgy Tikhomirov • Received 17 February 2019 • Accepted 22 April 2019 • Published 17 May 2019

Citation: Andrianova ON, Golovko YYe, Manturov GN (2019) Verification of the ROSFOND/ABBN nuclear data based on the OECD/NEA benchmark on criticality safety of mox-fueled systems. Nuclear Energy and Technology 5(2): 91-96. https://doi. org/10.3897/nucet.5.35577

\begin{abstract}
The paper presents the results of a computational analysis of the OECD/NEA benchmark conducted to estimate the accuracy of the critical safety parameters of multiplying MOX-fueled systems. The computational test is a set of 15 spherical multiplying systems that differ in their compositions and geometries. According to the test conditions, the $k_{\text {eff }}$ values of the analyzed systems are unknown in advance. As part of the computational analysis of the test involving national codes and nuclear data libraries, along with the $k_{\text {eff }}$ calculations, it is also necessary to estimate the a priori (due to the accuracy of the nuclear data used) and a posteriori (based on the accumulated experimental information) errors in the calculated $k_{\text {eff }}$ values. Based on the benchmark, an updated version of the ROSFOND/ABBN-RF nuclear data was tested. The results of estimating the a priori and a posteriori errors in $k_{\text {eff }}$ using the INDECS system for the proposed test models are presented. The analysis of the calculated data shows that (1) the observed spread in the $k_{\text {eff }}$ values obtained from the Russian ROSFOND library and foreign evaluated nuclear data libraries (ENDF/B-VII.0, JEFF-3.2, JENDL-4.0) varies from -0.3 up to $0.8 \%$; and (2) the deviation of the calculation results in the $k_{\text {eff }}$ values obtained from the ROSFOND library and its group version, ABBN-RF, does not exceed $0.1 \%$. The average a priori error in $k_{\text {eff }}$ for all the tested options of multiplying systems is about $1 \%$ and, taking into account the selected set of experimental criticality data for MOX-fueled systems, including experiments at the BFS facilities, the average a posteriori error in $k_{\text {eff }}$ can be reduced to $0.3 \%$. The performed estimations confirm the high accuracy of the ROSFOND/ABBN-RF nuclear data for calculating the critical safety parameters of multiplying MOX-fueled systems.
\end{abstract}

\section{Keywords}

MOX fuel, integral experiments, BFS critical facility, accuracy estimation, effective multiplication factor, neutron data uncertainty, OECD/NEA benchmark, maximum likelihood method

\section{Introduction}

Following the main objective of the Organization for Economic Cooperation and Development Nuclear Energy
Agency (OECD/NEA) to contribute to the safe development of nuclear energy for peaceful purposes in the participating countries through international scientific and technical cooperation, the Agency's various expert and

* Russian text published: Izvestiya vuzov. Yadernaya Energetika (ISSN 0204-3327), 2018, n. 3, pp. 160-170. 
working groups, along with collecting, analyzing and improving neutron data libraries, computational methods, programs, and experimental databases, pay considerable attention to the development and computational analysis of various benchmark tests (OECD/NEA 2018). Such tests are the most effective means of testing specialized national codes and neutron data libraries.

Under the auspices of the OECD/NEA, nuclear and critical safety issues are addressed by the Working Party on Nuclear Criticality Safety (WPNCS) Expert Group, which includes a separate Working Expert Group on Uncertainty Analysis for Criticality Safety Assessment (EGUACSA) (Web-page of WPNCS 2018).

The EGUACSA experts were offered a "blind" computational benchmark test for estimating errors in calculating the effective neutron multiplication factor, $k_{\text {eff }}$, (the $k_{\text {eff }}$ values of the analyzed systems were unknown in advance) for simplified models of external MOX fuel cycle systems, which makes it possible to test national calculation codes and nuclear data used to substantiate the critical safety of projected reactor plants and external fuel cycle systems. As part of the test, tasks were also set to estimate the accuracy of the calculated predictions, reduce the a priori error by involving the results of previously performed integral and reactor-physical experiments, and adjust the neutron cross-sections.

Based on this benchmark test, a cycle of studies was performed at the JSC "SSC RF-IPPE n.a. A.I. Leipunsky" on verification of the ROSFOND/ABBN-RF nuclear data (Zabrodskaya et al. 2007, Andrianova et al. 2012) and validation of the software and methodological base of the INDECS system of codes and data archives (Manturov 2017, Manturov et al. 2017). The INDECS system includes the covariance neutron cross-sections data from ABBN (Andrianova et al. 2014) and the statistical analysis program of calculational-experimental results, which make it possible to quantify both the a priori (due to the existing errors in the nuclear data) and a posteriori (based on the information from the archives of experimental data) errors in the calculated $k_{\text {eff }}$ values.

\section{Critical safety benchmark test specification}

The proposed computational test is a simplified model of an external MOX fuel cycle system with a simple spherical geometry (Fig. 1). The spheres of fissile material of different diameters (from 15 to $52.5 \mathrm{~cm}$ ) and different fuel compositions (mixtures of uranium, plutonium and water) with densities of $3.5,5.5$ and $4.6 \mathrm{~g} / \mathrm{cm}^{3}$ are surrounded by a water reflector of a fixed thickness $(20 \mathrm{~cm})$. The considered multiplying systems are of the type of systems with an intermediate neutron spectrum.

The ratios of even-odd isotopes of plutonium $\left({ }^{239} \mathrm{Pu}\right.$, ${ }^{240} \mathrm{Pu},{ }^{241} \mathrm{Pu},{ }^{242} \mathrm{Pu}$ ) for the proposed fuel compositions (plutonium vector) correspond to the plutonium vector of MOX fuel used in SFR and LWR plants. The task is set in this way because of the interest in studying the influence of plutonium nuclear properties and characteristics due to changes in the plutonium vector in the $\mathrm{PuO}_{2}$ fuel compositions as well as water slowing properties on the critical mass. Table 1 shows the main characteristics of the benchmark multiplying systems. The corresponding

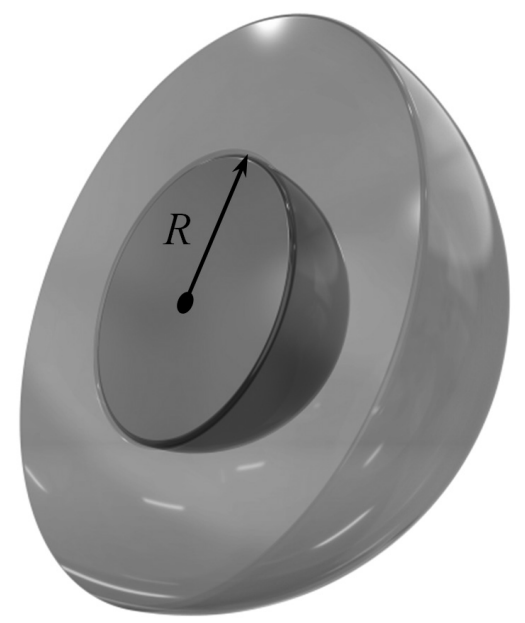

Figure 1. Computational benchmark test geometry

Table 1. Composition and geometry of the multiplying systems

\begin{tabular}{|c|c|c|c|c|c|c|c|}
\hline Test option & $\mathbf{M}_{\mathrm{H} 2 \mathrm{O}} / \mathbf{M}_{\mathrm{U} 02+\mathrm{PuO} 2}$ & Radius, cm & $\mathbf{M}_{\mathrm{PuO} 2} / \mathbf{M}_{\mathrm{UO2}+\mathrm{PuO} 2}$ & ${ }^{239} \mathbf{P u} / \mathbf{P u}$ & ${ }^{240} \mathrm{Pu} / \mathrm{Pu}$ & ${ }^{241} \mathrm{Pu} / \mathrm{Pu}$ & ${ }^{242} \mathrm{Pu} / \mathrm{Pu}$ \\
\hline 1 & 2 & 3 & 4 & 5 & 6 & 7 & 8 \\
\hline 1 & $3 \%$ & 17.0 & $100 \%$ & & & & \\
\hline 2 & $3 \%$ & 22.5 & $30 \%$ & $71 \%$ & $17 \%$ & $11 \%$ & $1 \%$ \\
\hline 3 & $3 \%$ & 46.0 & $12.5 \%$ & & & & \\
\hline 4 & $3 \%$ & 17.7 & $100 \%$ & & & & \\
\hline 5 & $3 \%$ & 24.1 & $30 \%$ & $64 \%$ & $23 \%$ & $10 \%$ & $3 \%$ \\
\hline 6 & $3 \%$ & 52.5 & $12.5 \%$ & & & & \\
\hline 7 & $3 \%$ & 15.0 & $100 \%$ & & & & \\
\hline 8 & $3 \%$ & 19.0 & $30 \%$ & $96 \%$ & $4 \%$ & $0 \%$ & $0 \%$ \\
\hline 9 & $3 \%$ & 40.0 & $12.5 \%$ & & & & \\
\hline 10 & $1 \%$ & 17.0 & $100 \%$ & & & & \\
\hline 11 & $1 \%$ & 22.5 & $30 \%$ & $71 \%$ & $17 \%$ & $11 \%$ & $1 \%$ \\
\hline 12 & $1 \%$ & 46.0 & $12.5 \%$ & & & & \\
\hline 13 & $5 \%$ & 17.0 & $100 \%$ & & & & \\
\hline 14 & $5 \%$ & 22.5 & $30 \%$ & $71 \%$ & $17 \%$ & $11 \%$ & $1 \%$ \\
\hline 15 & $5 \%$ & 46.0 & $12.5 \%$ & & & & \\
\hline
\end{tabular}


columns of the table indicate as follows: (1) conventional names of the multiplying systems; (2) fuel moisture (water mass-to-fuel mass ratio); (3) radius of the central part of the sphere shown in Fig. 1, filled with a mixture of MOX fuel and water; (4) $\mathrm{PuO}_{2}$ content in the fuel; (5-8) relative shares of plutonium isotopes.

The benchmark test specification defines the following design characteristics calculated using the ROSFOND/ ABBN-RF nuclear data library:

- Effective multiplication factor, $k_{\text {eff }}$

- One-group integral sensitivity coefficients to $k_{\text {eff }}$ of all isotopes that make up the fuel compositions;

- The a priori constant error in $k_{\text {eff }}$ due to the uncertainties in covariance nuclear data;

- A list of integral experiments selected to adjust the calculated $k_{\text {eff }}$ predictions;

- The a posteriori error in $k_{\text {eff }}$ obtained with account of the selected integral experiments by adjusting the nuclear data on the basis of the approaches, methods and codes implemented in the INDECS system.

This benchmark test is primarily aimed at verifying methods for determining displacements and errors in the $k_{\text {eff }}$ values and testing libraries of evaluated nuclear data and cross-sections uncertainties. Since the test itself is purely computational (there is no comparison with experimental data), according to the benchmark conditions, the $k_{\text {eff }}$ values were assumed to be unknown. This circumstance makes it impossible to focus the calculations on a previously known result; therefore, the emphasis in the analysis shifts from a comparison of the calculated and experimental discrepancies to an analysis of the spread in the calculated data obtained from different libraries (the so-called observed constant error). This task setting allows us to test the computational methods and codes used to improve the accuracy in estimating the a posteriori and a priori constant errors.

\section{Computational methods and results}

The a posteriori and a priori constant errors were estimated using the INDEX system of codes and data archives. The basis of computational methods implemented in the INDEX system is the maximum likelihood method (Usachev and Bobkov 1972). The capabilities of this method are verified and demonstrated in (Golovko et al. 2014, Ivanova et al. 2012, Golovko 2012). The method consists in finding the most credible corrections to the variable parameters (neutron cross sections), accounting for which allows us to obtain the best agreement between the calculated and experimental values for the functional of interest (in this case, $k_{\text {eff }}$ ) in the group of experiments under consideration. This is achieved by finding the maximum of the likelihood function $L$, which has the form (up to an insignificant factor) $\exp \left(-Z^{2} / 2\right)$, where the value of $Z^{2}$ in the exponent is determined by the relation

$$
Z^{2}=\mathbf{S} \cdot \mathbf{W}^{-1} \cdot \mathbf{S}^{\mathrm{T}}+\left(\Delta \mathbf{k}+\mathbf{H}^{\mathrm{T}} \cdot \mathbf{S}\right) \cdot \mathbf{U}^{-1}\left(\Delta \mathbf{k}+\mathbf{H}_{\mathrm{T}} \cdot \mathbf{S}\right)^{\mathrm{T}},
$$

where $\mathbf{S}$ is the desired vector of corrections to the parameters; $\mathbf{H}$ is the matrix of coefficients of $k_{\text {eff }}$ sensitivity to the parameters; $\mathbf{U}$ and $\mathbf{W}$ are the covariance matrices of cross-sections uncertainties of the experimental results (the $k_{\text {eff }}$ values) and desired parameters (neutron cross sections); $\Delta \mathbf{k}$ is the vector of discrepancies between the calculated and experimental $k_{\text {eff }}$ values.

From expression (1), we can obtain the relation for the desired corrections:

$$
\mathbf{S}=\mathbf{W} \cdot \mathbf{H}^{\mathrm{T}} \cdot\left(\mathbf{U}+\mathbf{H} \cdot \mathbf{W} \cdot \mathbf{H}^{\mathrm{T}}\right)^{-1} \boldsymbol{\Delta} \mathbf{k}
$$

and also the expression for the covariance matrix of the parameters $\mathbf{W} \phi$, which takes into account the corrections found:

$$
\mathbf{W}^{\prime}=\mathbf{W}-\mathbf{W} \cdot \mathbf{H} \cdot\left(\mathbf{U}+\mathbf{H} \cdot \mathbf{W} \cdot \mathbf{H}^{\mathrm{T}}\right)^{-1} \Delta \mathbf{k} .
$$

By means of the matrix $\left(\mathbf{W}^{\prime}\right)$, we can estimate the new matrix $\left(\mathbf{V}^{\prime}\right)$ of the expected calculated errors using corrected constants, the a posteriori constant calculation error taking into account the data of integral experiments and corrections to the calculated $\Delta \mathbf{k}^{\prime}$ :

$$
\begin{gathered}
\mathbf{V}^{\prime}=\mathbf{H} \cdot \mathbf{W}^{-1} \cdot \mathbf{H}^{\mathrm{T}}, \\
\boldsymbol{\Delta} \mathbf{k}^{\prime}=\boldsymbol{\Delta} \mathbf{k}+\mathbf{H}^{\mathrm{T}} \cdot \mathbf{S} .
\end{gathered}
$$

The $k_{\text {eff }}$ values for the proposed test options were calculated by the MCNP code (MCNP 2008) using the ROSFOND/ABBN-RF nuclear data library and other libraries of evaluated nuclear data (ENDF/B-VII.0, JEFF-3.2, JENDL-4.0). Table 2 shows the comparison results, based on which (Column 2), it follows that the $k_{\text {eff }}$ values obtained from the ROSFOND library of evaluated neutron data and its group version, ABBN-RF, agree within $0.1 \%$. At the same time, the average discrepancies between the calculated $k_{\text {eff }}$ values and the evaluated nuclear data obtained from the ROSFOND library and foreign libraries do not exceed $0.25 \%$.

The spread in the $k_{\text {eff }}$ values calculated using various libraries of evaluated nuclear data lies in the range from -0.26 to $0.79 \%$. The maximum discrepancies correspond to Option 7, in which only $\mathrm{PuO}_{2}$ is included in the fuel composition, with a maximum content of the ${ }^{239} \mathrm{Pu}$ isotope equal to $96 \%$.

The analysis of the one-group sensitivity coefficients showed that the options with large values of coefficients of $k_{\text {eff }}$ sensitivity to ${ }^{239} \mathrm{Pu}$ neutron cross sections (Fig. 2), in particular, Options 7 and 8, have the greatest discrepancy in the $k_{\text {eff }}$ values calculated using different libraries of evaluated nuclear data (the best agreement in the other options can be explained by the error compensation in the constants of other plutonium and uranium isotopes). Since the values of the one-group coefficients of $k_{\text {eff }}$ sensitivity to ${ }^{239} \mathrm{Pu}$ neutron cross sections are an order of magnitude higher than the values of the sensitivity coefficients 
Table 2. Comparison of calculation results for different nuclear data systems

\begin{tabular}{ccccc}
\hline Test option & ABBN-RF/ ROSFOND & ENDF/B-VII/ ROSFOND & JEF-3.2/ ROSFOND & JENDL-4.0/ ROSFOND \\
\hline 1 & $0.07 \%$ & $0.21 \%$ & $-0.25 \%$ & $0.10 \%$ \\
2 & $-0.01 \%$ & $0.21 \%$ & $-0.12 \%$ & $0.04 \%$ \\
3 & $-0.09 \%$ & $0.07 \%$ & $-0.16 \%$ & $-0.06 \%$ \\
4 & $0.07 \%$ & $0.28 \%$ & $-0.07 \%$ & $0.21 \%$ \\
5 & $-0.02 \%$ & $0.22 \%$ & $-0.13 \%$ & $0.04 \%$ \\
6 & $-0.07 \%$ & $0.07 \%$ & $0.36 \%$ & $-0.06 \%$ \\
7 & $0.02 \%$ & $0.71 \%$ & $0.34 \%$ & $0.79 \%$ \\
8 & $-0.03 \%$ & $0.48 \%$ & $0.21 \%$ & $0.42 \%$ \\
9 & $-0.08 \%$ & $0.28 \%$ & $-0.26 \%$ & $0.22 \%$ \\
10 & $0.07 \%$ & $0.18 \%$ & $-0.11 \%$ & $0.15 \%$ \\
11 & $0.05 \%$ & $0.18 \%$ & $-0.23 \%$ & $-0.04 \%$ \\
12 & $0.04 \%$ & $0.19 \%$ & $-0.23 \%$ & $-0.05 \%$ \\
13 & $0.06 \%$ & $0.24 \%$ & $-0.02 \%$ & $0.22 \%$ \\
14 & $-0.07 \%$ & $0.15 \%$ & $-0.03 \%$ & $0.05 \%$ \\
\hline
\end{tabular}

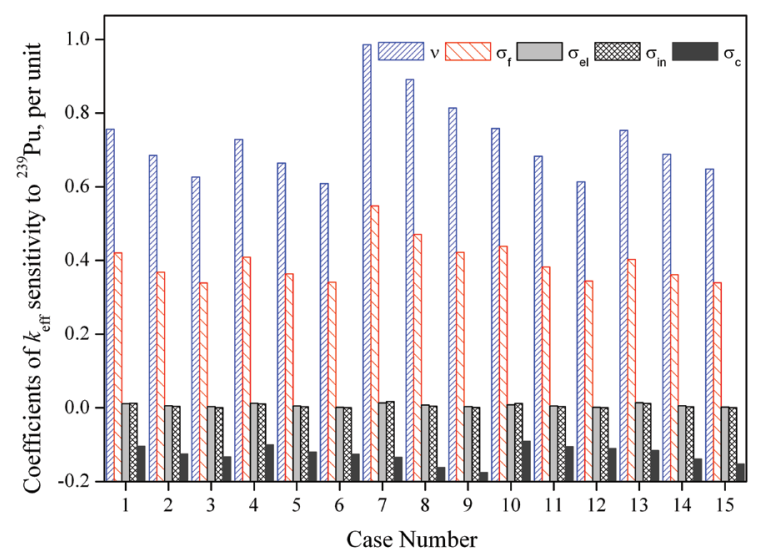

Figure 2. Coefficients of $k_{\text {eff }}$ sensitivity to ${ }^{239} \mathrm{Pu}$ cross sections for different benchmark-test models

to neutron cross sections of other fuel isotopes $\left({ }^{238} \mathrm{U},{ }^{235} \mathrm{U}\right.$, ${ }^{240-242} \mathrm{Pu}$ ), it can be concluded that the observed discrepancies in the $k_{\text {eff }}$ values are due to the spread in neutron data for the ${ }^{239} \mathrm{Pu}$ isotope presented in various libraries of evaluated nuclear data.

To estimate the a posteriori error of the models under consideration, experiments were selected from the International Criticality Safety Benchmark Evaluation Project (ICSBEP) Handbook (ICSBEP 2018). The data of these benchmark experiments were used in (Golovko and Manturov 2017, Golovko et al. 2008, Andrianova et al. 2017, Andrianova et al. 2016) to estimate the accuracy of calculations of external MOX fuel cycle systems. Table 3 presents a list of 101 benchmark experiments that include homogeneous solutions with plutonium (PST-identifier) and mixtures of uranium and plutonium (MST-identifier) as well as benchmark models of experiments performed at the large physical test facilities BFS-1 and -2 (Doulin et al. 2007a, b, c).

Based on the covariance matrices of neutron cross sections for the ABBN group library, according to formula (4), the values of the relative a priori constant error in $\delta k_{\text {eff }}$ calculated for all the 15 benchmark models were obtained (see Table 4).
Table 3. List of benchmark experiments

\begin{tabular}{|c|c|c|c|c|c|}
\hline No. & $\begin{array}{c}\text { Experiment } \\
\text { identifier in } \\
\text { ICSBEP }\end{array}$ & $\begin{array}{c}\text { Critical } \\
\text { configuration } \\
\text { identifier }\end{array}$ & No. & $\begin{array}{c}\text { Experiment } \\
\text { identifier in } \\
\text { ICSBEP }\end{array}$ & $\begin{array}{c}\text { Critical } \\
\text { configuration } \\
\text { identifier }\end{array}$ \\
\hline 1 & PST001 & $1-6$ & 19 & PST032 & $2,6,11$ \\
\hline 2 & PST002 & 1,7 & 20 & PMF001 & 1 \\
\hline 3 & PST003 & 1,5 & 21 & PMF002 & 1 \\
\hline 4 & PST004 & $3,5,6,13$ & 22 & PMF011 & 1 \\
\hline 5 & PST005 & 1,9 & 23 & PMF022 & 1 \\
\hline 6 & PST006 & 2 & 24 & PMF024 & 1 \\
\hline 7 & PST009 & 3 & 25 & PMF027 & 1 \\
\hline 8 & PST010 & $1-3,9,11$ & 26 & PMF029 & 1 \\
\hline 9 & PST011 & 1,8 & 27 & PMF031 & 1 \\
\hline 10 & PST012 & $7-13$ & 28 & MST002 & 2,3 \\
\hline 11 & PST018 & $1,5,9$ & 29 & MST003 & $4,7,9,10$ \\
\hline 12 & PST020 & $3,5,8,9$ & 30 & MST004 & $2,5,7$ \\
\hline 13 & PST021 & $1,3,4$ & 31 & MST005 & $2,3,4,7$ \\
\hline 14 & PST022 & $1,2,3,8$ & 32 & MST006 & 1 \\
\hline 15 & PST023 & $1,8,17,34$ & 33 & MST007 & 1 \\
\hline 16 & PST025 & $\begin{array}{c}3,10,17,22 \\
31,36,42\end{array}$ & 34 & MST010 & 1 \\
\hline 17 & PST026 & 3,16 & & & $31-5,38-2,42,97-1$, \\
\hline 18 & IMF007 & 1 & 35 & BFS & $\begin{array}{c}97-2,97-3,97-4,99- \\
1,99-2,101-1,101- \\
2,101-2 \mathrm{~A}, 101-3\end{array}$ \\
\hline
\end{tabular}

Table 4. Benchmark a priori $\delta k_{\text {eff }}$ and a posteriori $\delta^{\prime} k_{\text {eff }}$ errors caused by the neutron cross section errors

\begin{tabular}{ccccccccc}
\hline No. & $\mathbf{d k}_{\mathrm{eff}} \mathbf{\%}$ & $\boldsymbol{\delta}^{\prime} \mathbf{k}_{\mathrm{eff}} \mathbf{\%}$ & $\mathbf{N o}$ & $\mathbf{d k}_{\mathrm{eff}} \boldsymbol{\%}$ & $\boldsymbol{\delta}^{\prime} \mathbf{k}_{\mathrm{eff}} \boldsymbol{\%}$ & $\mathbf{N o .}$ & $\mathbf{d k}_{\mathrm{eff}} \boldsymbol{\%}$ & $\boldsymbol{\delta}^{\prime} \mathbf{k}_{\mathrm{eff}} \boldsymbol{\%}$ \\
\hline 1 & 0.95 & 0.31 & 6 & 0.95 & 0.33 & 11 & 0.81 & 0.29 \\
2 & 0.84 & 0.32 & 7 & 1.16 & 0.22 & 12 & 0.81 & 0.28 \\
3 & 0.90 & 0.32 & 8 & 0.95 & 0.24 & 13 & 0.92 & 0.33 \\
4 & 0.93 & 0.31 & 9 & 0.95 & 0.22 & 14 & 0.89 & 0.35 \\
5 & 0.84 & 0.32 & 10 & 1.01 & 0.29 & 15 & 0.96 & 0.33 \\
\hline
\end{tabular}

Based on the experimental data (see Tab. 3), the maximum likelihood method was used to estimate the corrections to the $k_{\text {eff }}$ values that take into account the most likely displacements of neutron constants obtained as a result of calculations within the limits of errors (corrected constants). The corrected $k_{\text {eff }}$ values corresponding to these constants are shown in Fig. 3. The corrected error covariance matrix formed as a result of calculations made it 


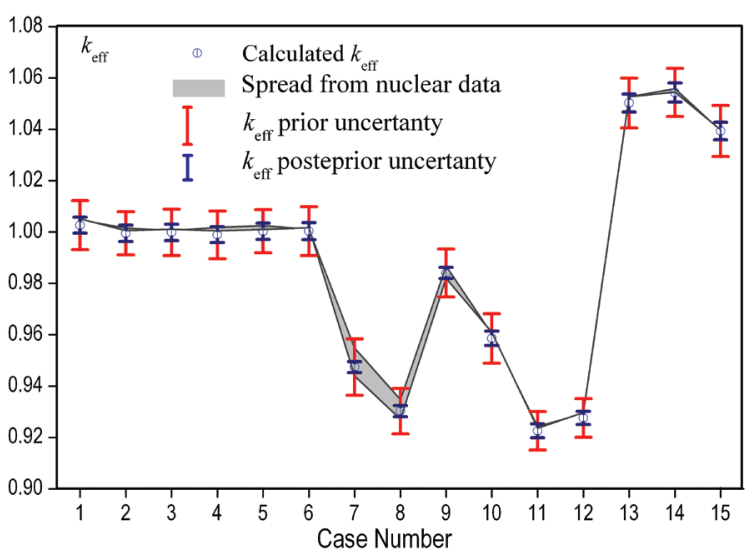

Figure 3. Summary of benchmark test calculation results

possible to calculate the a posteriori constant error in $k_{\text {eff }}$ , which is presented in Table. 3 (designated as $\delta^{\prime} k_{\text {eff }}$ ) and in Fig. 3 (the figure also shows the a priori constant error and the spread in the $k_{\text {eff }}$ values calculated using different libraries of evaluated nuclear data). As can be seen, using the data on previously performed experimental studies of the integral MOX fuel characteristics, it is possible to reduce the constant error in $k_{\text {eff }}$ by three times (on average, from 1 to $0.3 \%$ ) for simple systems with an intermediate neutron spectrum.

\section{Conclusion}

In accordance with the calculation program of the OECD/ NEA numerical benchmark test to substantiate the critical safety of MOX-fueled systems proposed by the Expert
Group on Uncertainty Analysis for Criticality Safety Assessment (EGUACSA), a series of calculations were performed aimed at verifying the ROSFOND/ABBN-RF nuclear data library. The analysis of the calculated data shows that:

- The maximum deviation in the calculated $k_{\text {eff }}$ values obtained using different libraries of evaluated nuclear data (ENDF/B-VII.0, JEFF-3.2, JENDL-4.0), in comparison with the results obtained from the ROSFOND library, reaches $0.8 \%$. The a priori error in the calculated $k_{\text {eff }}$ value, caused by the uncertainty in the nuclear data and calculated using the ABBN covariance matrices data, ranges from 0.8 to $1.2 \%$. Thus, the estimated a priori constant error in $k_{\text {eff }}$ coincides with the observed spread in the calculated $k_{\text {eff }}$ values, which indicates the reliability of the data on the errors in the ABBN neutron cross sections.

- The maximum deviation in the calculated $k_{\text {eff }}$ values $\sim 0.8 \%$ and the maximum a priori error value $\sim 1.2 \%$ correspond to Option 7 (the highest ${ }^{239} \mathrm{Pu}$ content in the fuel) and are caused by the spread in neutron data for this isotope in different libraries of evaluated nuclear data.

- The deviation in the calculated $k_{\text {eff }}$ values obtained from the ROSFOND library and its group version, ABBN-RF, does not exceed $0.1 \%$, which demonstrates the high accuracy of the ROSFOND/ABBNRF nuclear data for calculating the critical safety parameters of multiplying MOX-fueled systems.

- Using the data on previously performed experimental studies of the integral MOX fuel characteristics, it is possible to reduce the constant error in $k_{\text {eff }}$ by three times (on average, from 1 to $0.3 \%$ ) for simple systems with an intermediate neutron spectrum.

\section{References}

- Andrianova O, Golovko Yu, Zherdev G, Zadornov D, Koshcheev V, Manturov G, Peregudov A, Tsibulya A (2014) Testing Covariance Matrices in the ABBN Data System. Izvestia vuzov. Yadernaya energetika 2: 109-117. [in Russian]

- Andrianova O, Koshcheev V, Lomakov G, Manturov G (2017) Combined Use of Differential and Integral Experiments for Adjustment of Evaluated Nuclear Data. VANT. Ser.: Nuclear and Reactor Constants 1: 98-105. [in Russian]

- Andrianova O, Manturov G, Rozhikhin Ye (2016) Application of MCNP Non-analog Techniques for Calculations of Reaction Rate Measurements at the BFS Facilities. Izvestia vuzov. Yadernaya energetika 2: 66-76. [in Russian] https://doi.org/10.1016/j.nucet.2016.07.006

- Andrianova ON, Golovko YuE, Rozhikhin YeV, Yakunin AA (2012) Verification of the ABBN-RF group constant library on model problems and specially selected benchmark experiments. Yadernaya fizika i inzhiniring 3(2): 120-126. [in Russian]

- Doulin V, Kochetkov A, Pavlova O, Rozhikhin Y, Semenov M (2007a) BFS1 FUND EXP 003. Experimental Program Performed

at the BFS-42 Assembly k-infinity Experiments for ${ }^{238} \mathrm{U}$ in Fast Neutron Spectra: Measurements with Plutonium Mixed with Depleted Uranium Dioxide and Polyethylene. International Handbook of Evaluated Reactor Physics Benchmark Experiments. CD version, NEA/NSC/DOC (2007) 1.

- Doulin V, Kochetkov A, Pavlova O, Rozhikhin Ye, Semenov M (2007b) BFS2 FUND EXP 001. Experimental Program Performed at the BFS-31 Assembly k-infinity Experiments for ${ }^{238} \mathrm{U}$ in Fast Neutron Spectra: Measurements with Plutonium Mixed with Depleted Uranium Dioxide and Polyethylene. International Handbook of Evaluated Reactor Physics Benchmark Experiments. CD version, NEA/NSC/DOC (2007) 1.

- Doulin V, Kochetkov A, Pavlova O, Rozhikhin Ye, Semenov M (2007c) BFS2 FUND EXP 001. BFS-97, -99, -101 Assemblies: Experimental Program on Critical Assemblies with Heterogeneous Compositions of Plutonium, Depleted Uranium Dioxide, and Polyethylene. The International Handbook of Evaluated Reactor Physics Benchmark Experiments. CD version, NEA/NSC/ DOC (2007) 1. 
- Golovko Yu (2012) Application of the Undetermined Lagrangian Coefficients Method for Analyzing Consistency of Experiments: A Case Study of Systems with High Enriched Uranium from the ICSBEP Handbook. Izvestia vuzov. Yadernaya energetika 3: 5-15. [in Russian]

- Golovko Yu, Manturov G (2017) Application of the Undetermined Lagrangian Coefficients Method for Eliminating Contradictions in the Analysis of ICSBEP Benchmark Experiments on Criticality Safety. VANT. Ser.: Nuclear and Reactor Constants 2: 52-60. [in Russian]

- Golovko Yu, Rozhikhin Ye, Tsibulya A, Koshcheev V (2008) Evaluation of Accuracy of Calculational Criticality Prediction Based on ICSBEP Handbook Experiments. The Int. Conf. on the Physics of Reactors 2008, PHYSOR 2008, Interlaken, Switzerland: 1677-1684.

- Golovko YuYe, Koshcheev VN, Manturov GN, Tsibulya AM (2014) Applying the least squares method to estimate the constant error in criticality calculations of systems with plutonium. Yadernaya fizika i inzhiniring 5(4): 293. [in Russian]

- ICSBEP (2018) International Handbook of Evaluated Criticality Safety Benchmark Experiments. https://www.oecd-nea.org/science/ wpncs/icsbep/handbook.html [Access date: July 05, 2018]

- Ivanova T, Laville C, Dyrda J, Mennerdahl D, Golovko Y (2012) OECD/NEA Expert Group on Uncertainty Analysis for Criticality Safety Assessment: Results of Benchmark on Sensitivity Calculation (Phase III). The International Conference on the Physics of Reactors 2012, PHYSOR 2012: Advances in Reactor Physics, Knoxville, Tennessee, $2762-2780$.
- Manturov G (2017) Codes and Nuclear Data for Reactor Neutronics Calculations and Uncertainty Estimation. VANT. Ser.: Nuclear and Reactor Constants 1: 115-128. [in Russian]

- Manturov G, Koshcheev V, Nikolaev M, Peregudov A, Semenov M, Tsiboulia T (2017) System of Codes and Nuclear Data for Neutronics Calculations of Fast Reactors and Uncertainty Estimation. Proc. of the International Conference on Fast Reactors and Related Fuel Cycles: Next Generation Nuclear Systems for Sustainable Development (FR17). Ekaterinburg, Russian Federation, June 26-29. Conference ID 50810 (IAEA-CN245-475).

- MCNP - A General Monte Carlo N-Particle Transport Code (2008) Version 5, Volume I: Overview and Theory, LA-UR-03-1987, Los Alamos, 416 pp.

- OECD/NEA (2018) OECD/NEA web-site. https://www.oecd-nea. org/ [Access date: July 05, 2018]

- UACSA (2018) Web-page of WPNCS Expert Group on Uncertainty Analysis for Criticality Safety Assessment (UACSA). https://www. oecd-nea.org/science/wpncs/UACSA/ [Access date: July 05, 2018]

- Usachev L, Bobkov Y (1972) Planning on Optimum Set of Microscopic Experiments and Evaluations to Obtain a Given Accuracy in Reactor Parameter Calculations, INDC CCP-19U, IAEA Int. Nucl. Data Committee.

- Zabrodskaya SV, Ignatyuk AV, Koshcheev VN, Manokhin VN, Nikolaev MN, Pronyaev VG (2007) ROSFOND - Russian National Library of Evaluated Neutron Data. VANT. Ser.: Nuclear and Reactor Constants 12: 3-21. [in Russian] 